This article was published in Applied Microbiology and Biotechnology, 99(9), 3961-3969, 2015 http://dx.doi.org/10.1007/s00253-015-6389-4

\title{
Mismatch discrimination in fluorescent in situ hybridization using different types of nucleic acids
}

Fontenete Silvia \& Barros Joana \& Madureira Pedro \& Figueiredo Céu \& Wengel Jesper \& Azevedo Nuno Filipe

F. Silvia : B. Joana: A. N. Filipe ( $*)$

LEPABE—Laboratory for Process Engineering, Environment,

Biotechnology and Energy, Faculty of Engineering, University of Porto, Rua Dr. Roberto Frias, 4200-465 Porto, Portugal

e-mail: nazevedo@fe.up.pt

F. Silvia, F. Céu IPATIMUP, Institute of Molecular Pathology and Immunology of the University of Porto, 4200-465 Porto, Portugal

F. Silvia, W. Jesper

Nucleic Acid Center, Department of Physics, Chemistry and Pharmacy, University of Southern Denmark, 5230 Odense M, Denmark

F. Silvia, M. Pedro ICBAS, Institute of Biomedical Sciences Abel Salazar, University of

Porto, 4050-313 Porto, Portugal

B. Joana

INEB, Instituto de Engenharia Biomédica, 4150 Porto, Portugal

M. Pedro

IBMC, Institute for Molecular Biology and Cell Biology, 4150 Porto, Portugal

F. Céu

FMUP, Faculty of Medicine of Porto University, 4200-319 Porto, Portugal

\begin{abstract}
In the past few years, several researchers have focused their attention on nucleic acid mimics due to the increasing necessity of developing a more robust recognition of DNA or RNA sequences. Fluorescence in situ hybridization (FISH) is an example of a method where the use of these novel nucleic acid monomers might be crucial to the success of the analysis. To achieve the expected accuracy in detection, FISH probes should have high binding affinity towards their complementary strands and discriminate effectively the noncomplementary strands. In this study, we investigate the effect of different chemical modifications in fluorescent probes on their ability to successfully detect the complementary target and discriminate the mismatched base pairs by FISH. To our knowledge, this paper presents the first study where this analysis is per- formed with different types of FISH probes directly in biological targets, Helicobacter pylori and Helicobacter acinonychis. This is also the first study where unlocked nucleic acids (UNA) were used as chemistry modification in oligonucleotides for FISH methodologies. The effectiveness in detecting the specific target and in mismatch discrimination appears to be improved using locked nucleic acids
\end{abstract}


(LNA)/2'- $O$-methyl RNA (2'OMe) or peptide nucleic acid (PNA) in comparison to LNA/DNA, LNA/UNA, or DNA probes. Further, the use of LNA modifications together with 2 'OMe monomers allowed the use of shorter fluorescent probes and increased the range of hybridization temperatures at which FISH would work.

Keywords FISH $\cdot$ Oligonucleotides $\cdot$ Nucleic acids $\cdot$ Microbiology $\cdot$ Mismatch discrimination

\section{Introduction}

It has been shown that fluorescent in situ hybridization (FISH) is a very sensitive and specific method for microbial identification in clinical, industrial, and environmental samples (DeLong et al. 1989; Sekiguchi et al. 1999; Kempf et al. 2000). The success of this methodology relies on the specificity of oligonucleotide sequences to their complementary tar- get. Ideally, oligonucleotides should hybridize with fully complementary DNA or RNA sequences and fail to hybridize with sequences that contain one or more mismatches (Yan et al. 2012). However, it has been shown that for DNA sequences, this discrimination is often difficult to achieve (Kubota et al. 2006). More recently, other types of synthetic nucleic acids such as peptide nucleic acid (PNA) and locked nucleic acids (LNA) have been used in FISH with very promising results (Guimaraes et al. 2007; Mook et al.2007; Tavares et al. 2008; Campbell and Wengel 2011; Almeida et al. 2013; Cerqueira et al. 2013). To understand the specificity of these novel molecules towards DNA and RNA, several thermal dissociation studies have been conducted to analyze the effects of mismatches on duplex stability (Owczarzy et al. 2011; Yan et al. 2012; Matsumoto et al. 2013). However, this type of analysis has always been performed with naked DNA in standard chemical solutions. Therefore, it is not necessarily predictive of what occurs during a FISH procedure in which a chemically modified probe hybridizes to ribosomal RNA (rRNA) within a cellular microenvironment (Cerqueira et al. 2008).

In here, we evaluate the mismatch discrimination potential of different types ofDNA/RNA mimics used frequently in the literature for FISH, such as PNA, LNA, and 2'-O-methyl RNA (2'OMe), and also of a molecule that has not been previously used in FISH, named unlocked nucleic acids (UNA). Mismatch discrimination was assessed by both thermal dissociation studies and by FISH experiments. As a case study, we tested the discrimination of the sequences for two closely related Helicobacterspp., Helicobacter pylori and Helicobacter acinonychis (Marshall et al. 1984; Eaton et al. 1993). In fact, our group has been focused on the development of several FISH methodologies to detect Helicobacter species, namely using peptide nucleic acids (PNA) (Guimaraes et al. 2007; Cerqueira et al. 2011, 2013), locked nucleic acids (LNA), and 2'-O-methyl RNAs (2'OMe) (Fontenete et al. 2013). The novel oligonucleotides were purposely designed for a specific and conservative region in the $16 \mathrm{~S}$ rRNA of $H$. pylori that is also present, with a single mismatch, in $H$. acinonychis. Therefore, we evaluate how a single mismatch in the DNA or RNA target influences the hybridization stability and also report on the ability of different probes to discriminate between $H$. pylori and H. acinonychis, at a large range of temperatures. 


\section{Materials and methods}

Probe design

For mismatch discrimination, it was necessary to find a sequence which was identical within the two Helicobacter species with the exception of a single nucleotide. The 16S rRNA target region was selected based on a search conducted at the 16S rRNA database of the Ribosomal Database Project II (RDP-II), version 10 (http://rdp.cme.msu.edu/) The ribosomal sequence $5^{\prime}$ ATTACTGGAGAGACTAAGC-3', which allowed the detection of H. pylori, was selected. The $16 \mathrm{~S}$ sequence of $H$. acinonychis is similar except for the $\mathrm{G}$ (underlined) that in $H$. acinonychis is an A. We used different types of nucleic acids targeting H. pylori: LNA, 2'OMe, unlocked nucleic acid (UNA), PNA, and DNA (Table 1). Different designs of oligo- nucleotide probes were tested to find the best discrimination possible based on earlier published criteria to improve mismatch discrimination (Kumar et al. 1998; You et al. 2006; Langkjaer et al. 2009; Pasternak and Wengel 2010, 2011; Owczarzy et al. 2011). As DNA has a restricted flexibility of oligonucleotide design, only one probe was designed (Table 1). The length of this probe was selected based on the analysis of the Gibbs free energy $\left(\Delta G^{\circ}\right)$, which, according to Yilmaz et al.(Yilmaz et al. 2006), must be lower than $-13.5 \mathrm{kcal} / \mathrm{mol}$. The probe used in this study has a $\Delta G^{\circ}$ of $-16.63 \mathrm{kcal} / \mathrm{mol}$. Similarly, PNA also has a restricted flexibility of probe design as PNA cannot be mixed with nucleotide monomers like DNA, LNA, or UNA. In this case, and because there are no guidelines related to the minimum $\Delta G^{\circ}$, we based our design on our extensive experience in working with these probes (Guimaraes et al. 2007; Cerqueira et al. 2011, 2013). In contrast, LNA, 2'OMe, and UNA bases can be positioned anywhere within an oligonucleotide sequence, which means that the design is much more flexible and that probe fine- tuning is possible (You et al. 2006). As a general rule, these probes were designed with a triplet of LNA-modified nucleotides positioned at the center of the mismatch site to improve the discrimination (You et al. 2006; Owczarzy et al. 2011). The use of a higher density of LNA residues in each probe is an- other important parameter to improve mismatch discrimination (You et al. 2006). In the case of HyP_LNA/2'OMe probes (1 and 2) (Table 1), every second base was LNA modified as previously reported (Kierzek et al.2005).

\section{Oligonucleotide synthesis and purification}

The DNA oligonucleotide (HyP_DNA) attached to fluoresce- in phosphoramidite (FAM) was purchased from Sigma- Aldrich (St. Louis, USA). The PNA (HyP-PNA) probe was synthesized by Panagene (Daejeon, South Korea), and the probe $\mathrm{N}$ terminus was attached to an FAM molecule via a double 8-amino-3,6-dioxaoctanoic acid (AEEA) linker. Both probes were HPLC purified to reach a purity of $>90 \%$.

The remaining oligonucleotides were synthesized on an Expedite DNA synthesizer (PerSpective Biosystems, Expedite 8909 instrument) using standard phosphoramidite chemistry in $1.0 \mu \mathrm{moL}$ scale. The synthesized oligonucleotides were deprotected and cleaved from the solid support by treatment with $32 \%(v / v)$ aqueous ammonia solution for $12 \mathrm{~h}$ at $55{ }^{\circ} \mathrm{C}$ (UNA1_HPy, UNA2_HPy, UNA3_HPy, LNA1_HPy, and LNA2_HPy oligonucleotides) or with $98 \%(v / v)$ aqueous methanol/ammonia solution $7 \mathrm{~N}$ in methanol $(1: 1)$ for $2 \mathrm{~h}$ at RT, followed by an incubation with $32 \%(v / v)$ aqueous ammonia solution for $12 \mathrm{~h}$ at $55{ }^{\circ} \mathrm{C}\left(2^{\prime}\right.$ OMe1_HPy and 2'OMe2_HPy oligonucleotides). DNA and LNA monomers are commercially 
available from Proligo Reagents and Exiqon (Copenhagen, Denmark), respectively. UNA and 2'OMe monomers are commercially available from RiboTask (Langeskov, Denmark). All oligonucleotides were purified by reversed phase HPLC (RP-HPLC) and characterized by ion exchange HPLC conditions (IE-HPLC) on a Dionex system HPLC and matrix-assisted laser desorption ionization time-of-flight mass spectrometry (MALDI-TOF). The purified oligonucleotides were precipitated by acetone, and their purity ( $>90 \%)$ and composition were verified by IE-HPLC and MALDI-TOF analyses, respectively.

For thermal denaturation studies, unmodified DNA [HyP_DNA_Target: 5'd(GCTTAGTCTCTCCAGTAAT)-3'] and RNA oligonucleotides [HyP_RNA_Target: 5'-r(GCUU AGUCUCUCCAGUAAU)-3'] were purchased from Sigma- Aldrich and Integrated DNA Technologies (Leuven, Belgium), respectively. Also, the DNA sequence 5'-d(ATTA CTGGAGAGACTAAGC)-3' (HyP_DNA_Ref) that was used as a reference in thermal denaturation studies was purchased from Sigma-Aldrich.

\section{Thermal denaturation studies}

The thermal denaturation studies were performed following published protocols (Christensen et al. 2001; Perlikova et al. 2014). Melting curves of fully complementary and of one- mismatchcontaining oligonucleotide duplexes were recorded on a PerkinElmer LAMBDA $35 \mathrm{UV} / \mathrm{Vis}$ spectrometer equipment with a PTP 6 (Peltier Temperature Programmer) element (Massachusetts, USA). One micromolar of each strand was used in different types of melting buffers: medium salt buffer with $110 \mathrm{mM} \mathrm{Na}^{+}$(100 mM NaCl, $10 \mathrm{mM} \mathrm{NaH2PO4,} \mathrm{and} \mathrm{0.1} \mathrm{mM} \mathrm{EDTA;} \mathrm{pH} \mathrm{7.0);} \mathrm{low}$ salt buffer with $30 \%$ formamide and $10 \mathrm{mM} \mathrm{Na}^{+}(10 \mathrm{mM} \mathrm{NaCl}, 5 \mathrm{mM}$ EDTA, $50 \mathrm{mM}$ Tris- $\mathrm{HCl}$, and $30 \%(v / v)$ formamide; $\mathrm{pH} 7.5)$; and a high salt buffer with $4 \mathrm{M}$ of urea and $900 \mathrm{mM} \mathrm{Na}^{+}(900$ $\mathrm{mM} \mathrm{NaCl}, 5 \mathrm{mM}$ EDTA, $50 \mathrm{mM}$ Tris-HCl, and $4 \mathrm{M}$ of urea; $\mathrm{pH} 7.5$ ). The medium buffer is a standard buffer used in this type of studies. The low and the high salt buffers were used to mimic the buffers used in FISH experiments with bacterial cells. Each sample was mixed and the resulting complexes denatured by heating to $85{ }^{\circ} \mathrm{C}$ during $5 \mathrm{~min}$; samples were then cooled to the starting temperature of the experiment. Quartz optimal cells with a path length of $1.0 \mathrm{~cm}$ were used. Melting temperatures ( $T m$ values) were determined as the maximum of the first derivative of the thermal denaturation curve (A260 vs. temperature for medium salt buffer and high salt bufferwith $4 \mathrm{M}$ urea and A270 vs. temperature low salt buffer with $30 \%(v / v)$ formamide). Absorbance was monitored at $270 \mathrm{~nm}$ in the low salt buffer because of the inherent absorbance of formamide at 260 $\mathrm{nm}$ (Sadhu et al. 1984). A temperature range from 13 to $15^{\circ} \mathrm{C}$ to $80-85^{\circ} \mathrm{C}$ and a ramp of $1.0^{\circ} \mathrm{C} / \mathrm{min}$ were used. Reported $T_{m}$ values are an average of two measurements with- in $\pm 0.5^{\circ} \mathrm{C}$.

\section{Bacterial strains and culture conditions}

H. pylori 26695, obtained from the American Type Culture Collection (ATCC 700392, VA, USA) and H. acinonychis strain 90-119, obtained from the Health Protection Agency Culture Collections (HPA Culture Collections 12686, Salisbury, UK), were subcultured every $48 \mathrm{~h}$ in trypticase soy agar (TSA) supplemented with $5 \%(v / v)$ sheep blood (Becton Dickinson GmbH, Germany) and incubated at $37^{\circ} \mathrm{C}$ under microaerobic conditions using a GENbox microaer (bioMérieux, Marcy l'Étoile, France). Cell concentration was obtained by optical density (O. D.), 
and eachinitial culture was diluted in saline buffer in order to obtain a final concentration of $10^{6}$ total cells $/ \mathrm{mL}$.

Optimization of probe hybridization conditions

Different hybridization conditions were used, depending on the nucleic acid composition, length, and chemical nature of each probe. Therefore, we studied a large temperature range of $25-70{ }^{\circ} \mathrm{C}$ in pure cultures of $H$. pylori. For specificity analysis, we tested these probes for mismatch discrimination using $H$. acinonychis at temperatures for which probes showed higher sensitivity. All probes were optimized in FISH standard conditions (hybridization temperature, salt concentration, $\mathrm{pH}$, and formamide/urea concentration). To optimize the DNA- FISH protocol, we used different types of model protocols for DNA-FISH (Krimmer et al. 1999; Moreno et al. 2003), and we performed several adjustments for all steps. After fixation and cell disaggregation of each suspension (as previously described (Fontenete et al. 2013)), an extra permeabilization step was performed by adding $30 \mu \mathrm{L}$ lysozyme $(2 \mathrm{mg} / \mathrm{mL}$ in $10 \mathrm{mM}$ Tris- $\mathrm{HCl}(\mathrm{pH} 8))$ during $1 \mathrm{~h}$ at $37^{\circ} \mathrm{C}$. The fixed cells $(100 \mu \mathrm{L})$ were resuspended in equal volume of the hybridization solution $(0.9 \mathrm{M}$ $\mathrm{NaCl}, 20 \mathrm{mM}$ Tris-HCl [pH 7.5], $0.001 \%(v / v)$ sodium dodecyl sulfate (SDS), $30 \%(v / v)$ formamide, and $400 \mathrm{nM}$ of probe) and incubated at different temperatures for $90 \mathrm{~min}$. Samples were centrifuged at $16,873 \mathrm{~g}$ for $5 \mathrm{~min}$, resuspended in $500 \mu \mathrm{L}$ of washing solution $(0.64 \mathrm{M} \mathrm{NaCl}, 5$ $\mathrm{mM}$ Tris- $\mathrm{HCl}[\mathrm{pH} 7.5], 0.01 \%(v / v)$ SDS, $\mathrm{pH} 7)$, and incubated at the same temperature of hybridization for $20 \mathrm{~min}$. Samples were again centrifuged at $16,873 \mathrm{~g}$ for $5 \mathrm{~min}$ and resuspended in saline buffer. To remove aggregates, samples were filtered by a sterile filter with $10 \mu \mathrm{m}$ pore size (CellTrics $\left.{ }^{\circledR}\right)$ and were directly analyzed using flow cytometry.

The hybridization procedure for the PNA probe was similar to that used for the LNA probes (Guimaraes et al. 2007; Fontenete et al. 2013) however using a different type of hybridization buffer as described in Table 2. The hybridization method in suspension for LNA probes (LNA+DNA, LNA+2' OMe, and LNA+UNA) was based on procedures described by Fontenete et al. (Fontenete et al. 2013).

The ability of the oligonucleotides to discriminate the mismatch base pairs was then assessed by fluorescence intensity quantification studies (flow cytometry).

\section{Evaluation of rRNA level}

To confirm if the percentage of rRNA is similar in both of Helicobacter species, an universal peptide nucleic acid (PNA) EUB338 probe (5'Alexafluor 488-TGCCTCCCGT AGGA-3') which recognized a conserved region of the 16S rRNA in the domain bacteria (Amann et al. 1990) was used as a model probe. FISH experiments were performed as de- scribed above for PNA probes at $57^{\circ} \mathrm{C}$. Each experiment was performed in triplicate.

Flow cytometry and data analysis

Flow cytometry analysis was performed using an EPICS XL flow cytometer containing a lowpower air-cooled $15 \mathrm{~mW}$ blue $(488 \mathrm{~nm})$ argon laser. Data analysis was performed with the EXPO32ADC software (Beckman Coulter, Brea, USA). For each sample, 20,000 events were collected. All experiments were repeated in two runs (using three biological replicates of cultures 
for each run), and negative controls without probe were included for each type of protocol in every analysis. Flow cytometric analyses of samples were per- formed based on both scattering signals (forward scatter and side scatter) and FL-1. FAM fluorescence was detected on the FL-1 channel (BP530/30). For all detected parameters, amplification was carried out using logarithmical scales.

\section{Statistical analysis}

Statistical significance was determined by one-way analysis of variance (ANOVA) by applying the Tukey multiple comparison test, using SPSS ${ }^{\circledR}$ statistics 17.0 (Statistical Package for the Social Sciences (SPSS), Chicago, USA) or the Microsoft Office Excel ${ }^{\circledR}$ (Microsoft Corporation, Redmond, USA). Results were expressed as mean values. Differences were considered significant when $p<0.05$.

\section{Results}

Melting temperature analysis

The $T m$ values for the probes bound to fully complementary and single-mismatched targets are shown in Table 3 for the DNA target and in Table 4 for the RNA target. Because FISH hybridizations are performed in buffers of various compositions, we used different types of buffers with different ionic environments (different salt concentrations) and denaturing agents. In general, we observed an increase of $T m$ at higher salt-concentrated solutions and destabilization in the duplex strands when formamide was used. For oligonucleotides of similar lengths, LNA/2'OMe displayed the highest thermal stability in all buffers studied. LNA/DNA oligonucleotides also allowed the formation of relatively stable duplexes. The PNA oligonucleotide also showed a high stability in all buffers. The use of UNA monomers affected negatively the stability of the duplexes and as such the lowest melting temperatures in all buffers were obtained for these oligonucleotides (Table 4).

The specificity of the LNA and PNA oligonucleotides was confirmed by testing their ability to discriminate against mismatches in single-mismatched DNA and RNA strands (Tables 3 and 4 , respectively). Modified oligonucleotides exhibited better mismatch discrimination than the DNA oligomers, as confirmed by the higher $\Delta T m$ values. HyP_UNA/LNA oligonucleotides showed a high capacity of mismatch discrimination in medium salt buffer $(110 \mathrm{mM})$, and in some cases, no hybridization in the buffers with FA and urea was found with the single-mismatched strand. LNA/2'OMe oligo- nucleotides had the highest discrimination capacity in the high salt buffer with $4 \mathrm{M}$ of urea, even though HyP_LNA/DNA and PNA oligonucleotides also presented a strong specificity for this sequence.

Mismatch discrimination analysis in bacteria by flow cytometry studies

To analyze the efficiency of the probes in bacterial cells, we tested each probe in a range of temperatures between 25 and $70{ }^{\circ} \mathrm{C}$ measuring the fluorescence signal by flow cytometry. All FISH conditions used were the standard for each type of oligonucleotide; therefore, we used different buffers depending on whether we were using DNA, PNA, or LNA probes. 
The hybridization experiments were first performed with $H$. pylori as a target, in order to understand at which temperatures we could obtain a more efficient detection. The optimal hybridization temperature for each probe was considered as the temperature at which the hybridization with the microorganism of interest provided the strongest fluorescent signal and more specificity (weakest signal for the microorganism with the mismatch).

The subsequent experiments analyzed the capacity of mismatch discrimination. As a result, we performed FISH experiments with each probe in $H$. acinonychis, which had a single mismatch in the rRNA comparatively to $H$. pylori. As an example, Fig. 1 shows the results obtained for HyP_LNA/2_OMe1 for both microorganisms at different temperatures. From Fig. 1, we conclude that the hybridization temperature where the fluorescence intensity is higher for $H$. pylori is 45 ${ }^{\circ} \mathrm{C}$, whereas this hybridization temperature for $\mathrm{H}$. acinonychis is $30^{\circ} \mathrm{C}$. This appears to indicate a $\Delta T m$ for this probe of $15^{\circ} \mathrm{C}$, which compares with the $\Delta T m$ of $18.1^{\circ} \mathrm{C}$ obtained in the thermal dissociation studies for the buffer used for LNA probes $(900 \mathrm{mM} \mathrm{Na}+$ buffer with $4 \mathrm{M}$ urea). While these values are not very different, further studies would have to be performed to confirm that thermal dissociation studies provide an acceptable prediction of differences in hybridization temperatures between fully complementary and single- mismatched targets in FISH experiments.

The results of the FISH experiments for the optimal hybridization temperatures of $H$. pylori using the different probes can be analyzed in Fig. 2. The fluorescence intensity of the HyP_LNA/2'OMe1 and HyP_LNA/2'OMe2 probes is significantly higher in $H$. pylori than in $H$. acinonychis ( $p=0.028$ and $p=0.00$, respectively). The difference between the detection in $H$. pylori than $H$. acinonychis is also statistically significant in HyP_PNA $(p=0.001)$. On the other hand, no statistically significant differences were observed in terms of fluorescence intensity between the bacteria in study with HYP_DNA probe, HyP_LNA/UNA probes, and HyP_LNA/ DNA probes $(p>0.05)$.

In the specific conditions used for each experiment, LNA/ 2'OMe oligonucleotides showed the highest fluorescence signal of the oligonucleotides analyzed. The difference in fluorescence intensity is statistically significant $(p<0.05)$ between these probes and HyP_LNA/UNA and HyP_LNA/DNA2 probes. However, the PNA oligonucleotide represents a good alternative for these types of studies, since it showed a higher sensitivity and specificity at lower hybridization temperatures. LNA/DNA oligonucleotides showed distinct results, which were dependent on the length of the oligonucleotide. The shorter probe had similar results to the PNA oligonucleotide in terms of fluorescent intensity; however, the 11 mer oligo- nucleotides showed a very low capacity of hybridization with the target. Although the data from the melting behavior of this probe was very similar to those of the 9 merLNA/DNA probe, thehybridization in the bacteriarevealedverydifferent results. The same behavior was observed for the HyP_DNA probe.

For the evaluation of the rRNA level of each species of Helicobacter, we used EUB338 probe which targets both species. It was observed similar gates (percentage of cells identified by EUB338

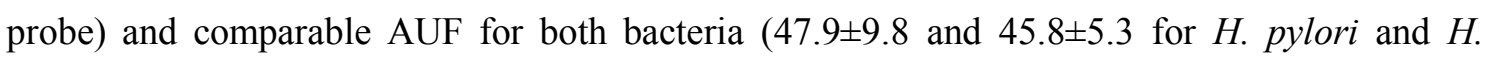
acinonychis, respectively). Therefore, there are not significant differences in rRNA levels between these bacteria. 


\section{Discussion}

The detection of microorganisms by FISH has significantly changed with the introduction of several types of synthetic oligonucleotides that possess a higher capacity of discrimination and affinity towards complementary sequences(Buchardt et al. 1993; Obika et al. 1997; Koshkin et al. 1998; Majlessi et al. 1998; Guimaraes et al. 2007; Guga and Koziolkiewicz 2011). Therefore, it is very important to discuss which type of nucleic acid mimics is more suitable for each specific situation, such as the recognition of mismatches. To tackle this issue, in this study, we analyzed the performance of different types of probes to discriminate mismatches, not only by thermal melting analysis of naked nucleic acids but also for specifically targeting bacterial cells with a FISH methodology.

To analyze the relationship between different types of probes and specificity, we performed melting studies for all probes with DNA and RNA targets. The use of different tar-gets is important because even though the FISH methodology is more frequently described for RNA targets, there arealso several studies using modified probes which use DNA as a target, e.g., (Celeda et al. 1994; Matthiesen and Hansen 2012). In accordance with the literature, a higher $T m$ was observed at higher salt-concentrated solutions (Owczarzy et al. 2004). Higher concentrations of $\mathrm{NaCl}$ allow the repulsion between the negatively charged oligonucleotides to be increasingly compensated by the positive counterions. However, this effect is smaller in one-mismatch duplexes because the two strands are further apart (Mishra et al. 2013). On the other hand, the use of formamide and urea was expected to allow for the destabilization in the duplex strands leading to lower melting temperatures (Yilmaz and Noguera 2007). However, this de- stabilization did not decrease the $T m$ to the same extent in the high salt buffer (Table 4). As expected, we observed a large difference in $T_{m}$ for all probes bound to fully complementary oligonucleotides vs. oligonucleotides containing one mismatch. The difference between the $T m$ values for each oligo- nucleotide was in agreement with the results published earlier (Filichev et al. 2004; Kaur et al. 2008; Pasternak and Wengel 2010). LNA/2'OMe and PNA showed high stability in all buffers, comparatively to LNA/DNA oligonucleotides. It has already been demonstrated that LNA and 2'OMe have different impacts on duplex stability, in spite of sharing a $C 3^{\prime}$-endo sugar pucker conformation (Yan et al. 2012). In general, we observed an increase of thermal duplex stability in the following order: HyP_LNA/UNA probes $<$ DNA probe $<$ HyP_LNA $/$ DNA probes $<$ HyP_PNA $=$ HyP_LNA $/ 2$ 'OMe probes (Table 4).

Usually, $T_{m}$ is used as an indication for the hybridization temperature because it is at this temperature half of the nucleic acid strands are forming a duplex and the other half are single stranded (SantaLucia et al. 1996). However, the hybridization temperature determined by experimental procedures in vitro is dependent of all biological parameters and chemical compounds involved in the hybridization step of a FISH procedure. These factors can be a cause for the absence of a pattern between these temperatures (Fontenete et al. in press). In fact, when we compare the discrimination temperature difference obtained by thermal studies with FISH under the same buffer conditions (Table 4), we can observe that statistically significant differences may arise $(p<0.05)$. Actually, it is highly unpredictable how each probe will hybridize in experiments with bacteria, because there are several factors that can affect the efficiency of the hybridization (Cerqueira et al. 2008). For instance, the diffusion through the extracellular membrane can be different for each probe (Politz et al. 1998). Therefore, we used the same standard parameters for all studied probes, and the experiments were performed under presumed optimal conditions. We have 
also assessed for the first time the use of HyP_LNA/UNA probes in FISH experiments. However, our results show that the use of UNA leads to a large destabilization in the duplex which affects the hybridization in bacteria (Table 4 and Fig. 2). Therefore, the use of UNA modifications in FISH probes may require the use of longer probes.

In general, nucleic acid mimics can indeed provide better mismatch discrimination than standard DNA probes in FISH, as it has been suggested previously (Stender et al. 2002; Guimaraes et al. 2007; Mishra et al. 2012, 2013). PNA with a low number of bases can broadly provide a good discrimination. Some studies have shown that LNA can increase single-base mismatch discrimination in bulk solutions (You et al. 2006). However, the design flexibility in LNA and 2' OMe oligonucleotides appears to indicate that the better performance should typically be obtained with these probes.

In this study, we showed that the analysis of probes using native targets allows a more realistic approach as it accounts for all variables that can interfere during the hybridization process. Methods that use only naked DNA for studying or comparing probes do not analyze the factors inside the cells that can interfere with the hybridization, e.g., molecular crowding and the presence of several solutes. As such, when several probes are compared, it is fundamental to analyze this behavior in terms of permeabilization or access to the target. For example, a molecule can have adequate thermodynamic parameters, but its chemistry may not be compatible with its use in a biological target. Therefore, approaches that combine naked and native targets contribute for a more complete and realistic study.

As a final conclusion, both $\mathrm{LNA} / 2^{\prime} \mathrm{OMe}$ and PNA probes are able to discriminate mismatches with a high signal-to- noise ratio, but LNA/2'OMe probes allow for a greater flexibility in probe design. Nonetheless, as probe design and optimum hybridization conditions vary for each type of probe, it is impossible to have an absolute certainty on which type of nucleic acid is better for mismatch discrimination. As such, for each specific sequence and mismatch, testing many possible probe designs and hybridization conditions with probes consisting of PNA and LNA/2'OMe is still advisable. Future work will focus on reassessing the impact of mismatches in a larger number of microorganisms which contain different types of cell wall, like Gram-positive bacteria and yeast cells.

\section{Acknowledgments}

This work was funded by the FEDER funds through the Operational Programme for Competitiveness Factors- COMPETE, ON.2-O Novo Norte-North Portugal Regional Operational Programme, and National Funds through FCT-Foundation for Science and Technology under the following projects: PEst-C/EQB/UI0511, NORTE-07-0124-FEDER000025-RL2_Environment and Health, DNA mimics Research Project PIC/IC/82815/2007, $\mathrm{PhD}$ grant [SFRH/BD/72999/2010], and Nucleic Acid Center, University of South- ern Denmark.

\section{Conflict of interest}

JW is a cofounder of RiboTask ApS which offers LNA/2'-OMe-RNA probes for RNA targeting. NFA is a cofounder of Biomode SA which develops molecular methods for the rapid detection of microorganisms. 


\section{References}

Almeida C, Azevedo NF, Bento JC, Cerca N, Ramos H, Vieira MJ, Keevil CW (2013) Rapid detection of urinary tract infections caused by Proteus spp. using PNA-FISH. Eur J Clin Microbiol Infect Dis 32(6):781-786

Amann RI, Binder BJ, Olson RJ, Chisholm SW, Devereux R, Stahl DA (1990) Combination of 16S rRNA-targeted oligonucleotide probes with flow cytometry for analyzing mixed microbial populations. Appl Environ Microbiol 56(6):1919-1925

Buchardt O, Egholm M, Berg RH, Nielsen PE (1993) Peptide nucleic acids and their potential applications in biotechnology. Trends Biotechnol 11(9):384-386

Campbell MA, Wengel J (2011) Locked vs. unlocked nucleic acids (LNA vs. UNA): contrasting structures work towards common therapeutic goals. Chem Soc Rev 40(12):5680-5689

Celeda D, Aldinger K, Haar FM, Hausmann M, Durm M, Ludwig H, Cremer C (1994) Rapid fluorescence in situ hybridization with repetitive DNA probes: quantification by digital image analysis. Cytometry 17(1):13-25

Cerqueira L, Azevedo NF, Almeida C, Jardim T, Keevil CW, Vieira MJ (2008) DNA mimics for the rapid identification of microorganisms by fluorescence in situ hybridization (FISH). Int $\mathrm{J}$ Mol Sci 9(10): 1944-1960

Cerqueira L, Fernandes RM, Ferreira RM, Carneiro F, Dinis-Ribeiro M, Figueiredo C, Keevil CW, Azevedo NF, Vieira MJ (2011) PNA- FISH as a new diagnostic method for the determination of clarithromycin resistance of Helicobacter pylori. BMC Microbiol 11:101

Cerqueira L, Fernandes RM, Ferreira RM, Oleastro M, Carneiro F, Brandao C, Pimentel-Nunes P, Dinis-Ribeiro M, Figueiredo C, Keevil CW, Vieira MJ, Azevedo NF (2013) Validation of a fluorescence in situ hybridization method using peptide nucleic acid probes for detection of Helicobacter pylori clarithromycin resistance in gastric biopsy specimens. J Clin Microbiol 51(6):1887-1893

Christensen U, Jacobsen N, Rajwanshi VK, Wengel J, Koch T (2001) Stopped-flow kinetics of locked nucleic acid (LNA)-oligonucleotide duplex formation: studies of LNA-DNA and DNADNA interactions. Biochem J 354(Pt 3):481-484

DeLong EF, Wickham GS, Pace NR (1989) Phylogenetic stains: ribosomal RNA-based probes for the identification of single cells. Science 243(4896):1360-1363

Eaton KA, Dewhirst FE, Radin MJ, Fox JG, Paster BJ, Krakowka S, Morgan DR (1993) Helicobacter acinonyx sp. nov., isolated from cheetahs with gastritis. Int J Syst Bacteriol 43(1):99-106

Filichev VV, Christensen UB, Pedersen EB, Babu BR, Wengel J (2004) Locked nucleic acids and intercalating nucleic acids in the design of easily denaturing nucleic acids: thermal stability studies. Chembiochem 5(12):1673-1679

Fontenete S, Guimaraes N, Leite M, Figueiredo C, Wengel J, Filipe Azevedo N (2013) Hybridization-based detection of Helicobacter pylori at human body temperature using advanced locked nucleic acid (LNA) probes. PLoS One 8(11):e81230

Fontenete S., N. Guimarães., J. Wengel, N.F. Azevedo (in press). Prediction of melting temperatures in fluorescence in situ hybridization (FISH) procedures using thermodynamic models. Crit Rev Biotechnol.

Guga P, Koziolkiewicz M (2011) Phosphorothioate nucleotides and oligonucleotides-recent progress in synthesis and application. Chem Biodivers 8(9):1642-1681

Guimaraes N, Azevedo NF, Figueiredo C, Keevil CW, Vieira MJ (2007) Development and 
application of a novel peptide nucleic acid probe for the specific detection of Helicobacter pylori in gastric biopsy specimens. J Clin Microbiol 45(9):3089-3094

Kaur H, Wengel J, Maiti S (2008) Thermodynamics of DNA-RNA heteroduplex formation: effects of locked nucleic acid nucleotides incorporated into the DNA strand. Biochemistry 47(4):1218-1227

Kempf VAJ, Trebesius K, Autenrieth IB (2000) Fluorescent in situ hybridization allows rapid identification of microorganisms in blood cultures. J Clin Microbiol 38(2):830-838

Kierzek E, Ciesielska A, Pasternak K, Mathews DH, Turner DH, Kierzek R (2005) The influence of locked nucleic acid residues on the thermodynamic properties of 2'-O-methyl RNA/RNA heteroduplexes. Nucleic Acids Res 33(16):5082-5093

Koshkin AA, Singh SK, Nielsen P, Rajwanshi VK, Kumar R, Meldgaard M, Olsen CE, Wengel J (1998) LNA (Locked Nucleic Acids): synthesis of the adenine, cytosine, guanine, 5methylcytosine, thymine and uracil bicyclonucleoside monomers, oligomerisation, and unprecedented nucleic acid recognition. Tetrahedron 54(14):3607- 3630

Krimmer V, Merkert H, von Eiff C, Frosch M, Eulert J, Lohr JF, Hacker J, Ziebuhr W (1999) Detection of Staphylococcus aureus and Staphylococcus epidermidis in clinical samples by 16S rRNA- directed in situ hybridization. J Clin Microbiol 37(8):2667-2673

Kubota K, Ohashi A, Imachi H, Harada H (2006) Improved in situ hybridization efficiency with locked-nucleic-acid-incorporated DNA probes. Appl Environ Microbiol 72(8):5311-5317

Kumar R, Singh SK, Koshkin AA, Rajwanshi VK, Meldgaard M, Wengel J (1998) The first analogues of LNA (locked nucleic acids):phosphorothioate-LNA and 2'-thio-LNA. Bioorg Med ChemLett 8(16):2219-2222

Langkjaer N, Pasternak A, Wengel J (2009) UNA (unlocked nucleic acid): a flexible RNA mimic that allows engineering of nucleic acid duplex stability. Bioorg Med Chem 17(15):5420-5425

Majlessi M, Nelson NC, Becker MM (1998) Advantages of 2'-O-methyl oligoribonucleotide probes for detecting RNA targets. Nucleic Acids Res 26(9):2224-2229

Marshall BRH, Annear DI, Goodwin CS, Pearman JW, Warren JR, Armstrong JA(1984) Original isolation of Campylobacter pyloridis from human gastric mucosa. Microbiol Lett 25:83-88

Matsumoto K, Nakata E, Tamura T, Saito I, Aizawa Y, Morii T (2013) A peptide nucleic acid (PNA) heteroduplex probe containing an inosine-cytosine base pair discriminates a single-nucleotide difference in RNA. Chemistry 19(16):5034-5040

Matthiesen SH, Hansen CM (2012) Fast and non-toxic in situ hybridization without blocking of repetitive sequences. PLoS One 7(7): e40675

Mishra S, Ghosh S, Mukhopadhyay R (2012) Ordered self-assembled locked nucleic acid (LNA) structures on gold(111) surface with enhanced single base mismatch recognition capability. Langmuir 28(9):4325-4333

Mishra S, Ghosh S, Mukhopadhyay R (2013) Maximizing mismatch discrimination by surfacetethered locked nucleic acid probes via ionic tuning. Anal Chem 85(3):1615-1623

Mook OR, Baas F, de Wissel MB, Fluiter K (2007) Evaluation of locked nucleic acid-modified small interfering RNA in vitro and in vivo. Mol Cancer Ther 6(3):833-843

Moreno Y, Ferrus MA, Alonso JL, Jimenez A, Hernandez J (2003) Use of fluorescent in situ hybridization to evidence the presence of Helicobacter pylori in water. Water Res 37(9):22512256

Obika S, Nanbu D, Hari Y, Morio K-I, In Y, Ishida T, Imanishi T (1997) Synthesis of 2'-O,4'-Cmethyleneuridine and -cytidine. Novel bicyclic nucleosides having a fixed $\mathrm{C} 3$, -endo sugar 
puckering. Tetrahedron Lett 38(50):8735-8738

Owczarzy R, You Y, Moreira BG, Manthey JA, Huang L, Behlke MA, Walder JA (2004) Effects of sodium ions on DNA duplex oligomers: improved predictions of melting temperatures. Biochemistry 43(12):3537-3554

Owczarzy R, You Y, Groth CL, Tataurov AV (2011) Stability and mismatch discrimination of locked nucleic acid-DNA duplexes. Biochemistry 50(43):9352-9367

Pasternak A, Wengel J (2010) Thermodynamics of RNA duplexes modified with unlocked nucleic acid nucleotides. Nucleic Acids Res 38(19):6697-6706

Pasternak A, Wengel J (2011) Unlocked nucleic acid—an RNA modification with broad potential. Org Biomol Chem 9(10):3591-3597

Perlikova P, Karlsen KK, Pedersen EB, Wengel J (2014) Unlocked nucleic acids with a pyrenemodified uracil: synthesis, hybridization studies, fluorescent properties and i-motif stability. Chembiochem 15(1):146-156

Politz JC, BrowneES, WolfDE, Pederson T (1998) Intranuclear diffusion and hybridization state of oligonucleotides measured by fluorescence correlation spectroscopy in living cells. Proc Natl Acad Sci U S A 95(11):6043-6048

Sadhu C, Dutta S, Gopinathan KP (1984) Influence of formamide on the thermal-stability of DNA. J Biosci 6(6):817-821

SantaLucia J Jr, Allawi HT, Seneviratne PA (1996) Improved nearest- neighbor parameters for predicting DNA duplex stability. Biochemistry 35(11):3555-3562

Sekiguchi Y, Kamagata Y, Nakamura K, Ohashi A, Harada H (1999) Fluorescence in situ hybridization using 16S rRNA-targeted oligo- nucleotides reveals localization of methanogens and selected uncultured bacteria in mesophilic and thermophilic sludge granules. Appl Environ Microbiol 65(3):1280-1288

Stender H, Fiandaca M, Hyldig-Nielsen JJ, Coull J (2002) PNA for rapid microbiology. J Microbiol Methods 48(1):1-17

Tavares A, Inacio J, Melo-Cristino J, Couto I (2008) Use of fluorescence in situ hybridization for rapid identification of staphylococci in blood culture samples collected in a Portuguese hospital. J Clin Microbiol 46(9):3097-3100

Yan Y, Yan J, Piao X, Zhang T, Guan Y (2012) Effect of LNA- and OMeN-modified oligonucleotide probes on the stability and dis- crimination of mismatched base pairs of duplexes. J Biosci 37(2): 233-241

Yilmaz LS, Noguera DR (2007) Development of thermodynamic models for simulating probe dissociation profiles in fluorescence in situ hybridization. Biotechnol Bioeng 96(2):349-363

Yilmaz LS, Okten HE, Noguera DR (2006) Making all parts of the 16S rRNA of Escherichia coli accessible in situ to single DNA oligonucleotides. Appl Environ Microbiol 72(1):733-744

You Y, Moreira BG, Behlke MA, Owczarzy R (2006) Design of LNA probes that improve mismatch discrimination. Nucleic Acids Res 34(8):e60 


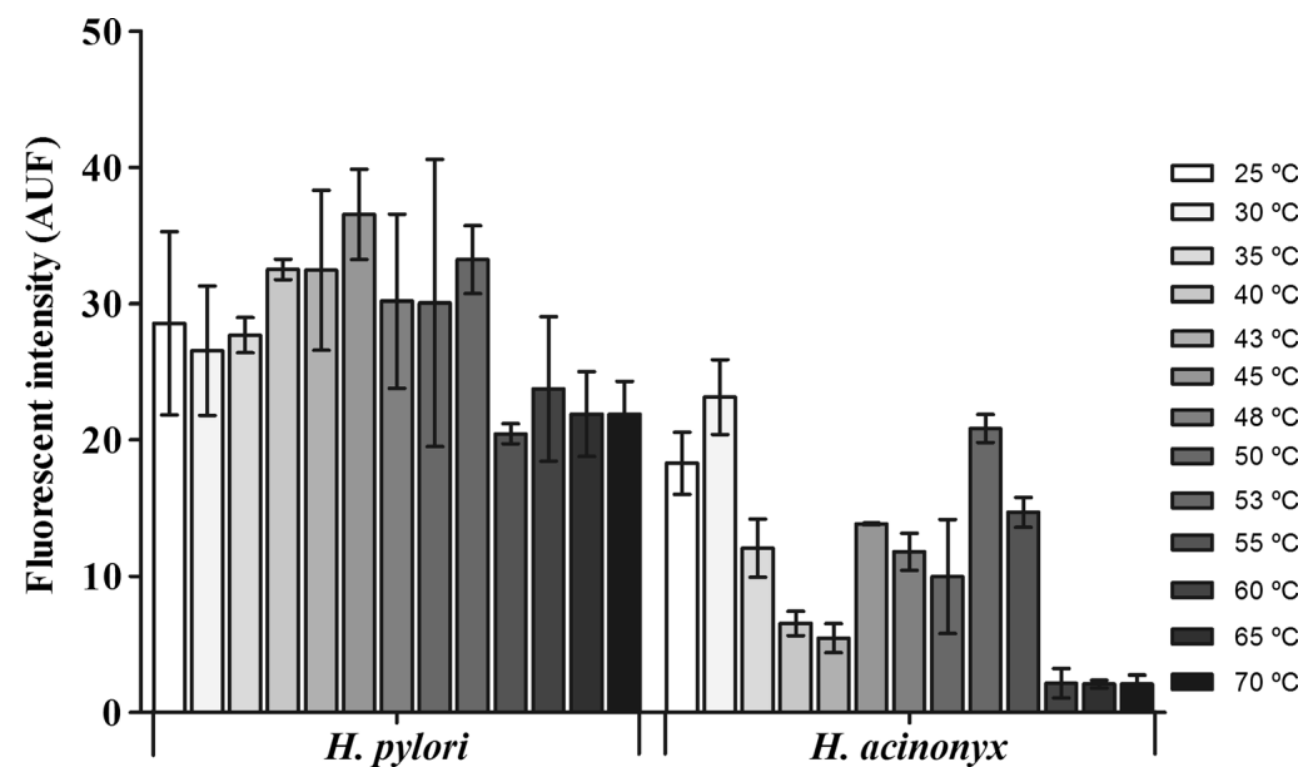

Fig. 1 The effect of the temperature on the specificity of HyP_LNA/2_OMe1 probe. Histogram showing the distribution of fluorescence intensity with the temperature in $H$. pylori and $H$. acinonychis

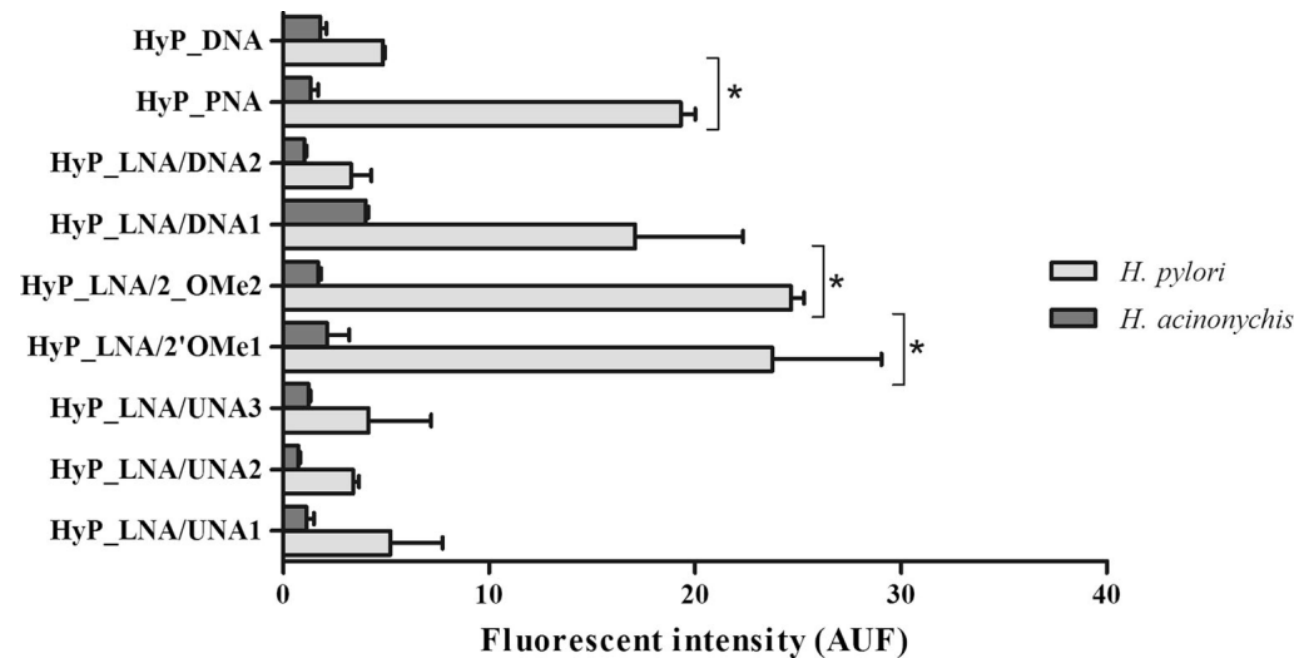

Fig. 2 FISH detection of $H$. pylori and $H$. acinonychis by cytometry at the optimal hybridization temperature. Quantification of the mean fluorescence intensity of each probe in two independent experiments. The optimal hybridization temperature for each probe is described in Table 4. The fluorescent signal intensity is expressed in arbitrary fluorescent units (AUF). The symbol asterisk (*) indicates the difference between $H$. pylori and $H$. acinonychis which is statistically significant $(p<0.05)$ 
Table 1 Sequence of the different oligonucleotide probes used in the present study. LNA nucleotide monomers are represented with L superscript, 2'-OMe-RNA monomers are represented with $\mathrm{m}$ superscript, DNA monomers are represented with italic $d$, and UNA monomers are represented with $\mathrm{u}$ and in boldface letters

\begin{tabular}{ll}
\hline Name & Sequence (5'FAM-3') \\
\hline HyP_DNA & $d$ (TTACTGGAGAGACTAAG) \\
HyP_PNA & CTGGAGAGACT \\
HyP_LNA/UNA1 & $\mathrm{T}^{\mathrm{L}} \mathrm{G}^{\mathrm{L}} \mathrm{uGA}^{\mathrm{L}} \mathrm{G}^{\mathrm{L}} \mathrm{AuGA} \mathrm{C}^{\mathrm{L}}$ \\
HyP_LNA/UNA2 & $\mathrm{C}^{\mathrm{L}} \mathrm{T}^{\mathrm{L}} \mathrm{uG}^{\mathrm{L}} \mathrm{A}^{\mathrm{L}} \mathrm{G}^{\mathrm{L}} \mathrm{A}^{\mathrm{L}} \mathrm{GuAC}^{\mathrm{L}} \mathrm{T}^{\mathrm{L}}$ \\
HyP_LNA/UNA3 & $\mathrm{C}^{\mathrm{L}} \mathrm{T}^{\mathrm{L}} \mathrm{GuGA}^{\mathrm{L}} \mathrm{G}^{\mathrm{L}} \mathrm{AuGA} \mathrm{C}^{\mathrm{L}} \mathrm{T}^{\mathrm{L}}$ \\
HyP_LNA/2'OMe1 & $\mathrm{U}^{\mathrm{m}} \mathrm{G}^{\mathrm{L}} \mathrm{G}^{\mathrm{m}} \mathrm{A}^{\mathrm{m}} \mathrm{G}^{\mathrm{L}} \mathrm{A}^{\mathrm{m}} \mathrm{G}^{\mathrm{L}} \mathrm{A}^{\mathrm{m}} \mathrm{C}^{\mathrm{m}}$ \\
HyP_LNA/2'OMe2 & $\mathrm{C}^{\mathrm{m}} \mathrm{U}^{\mathrm{L}} \mathrm{G}^{\mathrm{m}} \mathrm{G}^{\mathrm{m}} \mathrm{A}^{\mathrm{L}} \mathrm{G}^{\mathrm{m}} \mathrm{A}^{\mathrm{m}} \mathrm{G}^{\mathrm{L}} \mathrm{A}^{\mathrm{m}} \mathrm{C}^{\mathrm{m}} \mathrm{U}^{\mathrm{m}}$ \\
HyP_LNA/DNA1 & $\mathrm{T}^{\mathrm{L}} d \mathrm{GG}^{\mathrm{L}} d A \mathrm{G}^{\mathrm{L}} d \mathrm{AG}^{\mathrm{L}} d \mathrm{AC}$ \\
HyP_LNA/DNA2 & $\mathrm{C}^{\mathrm{L}} d \mathrm{~T} d \mathrm{G}^{\mathrm{L}} \mathrm{A}^{\mathrm{L}} \mathrm{G}^{\mathrm{L}} \mathrm{A}^{\mathrm{L}} d \mathrm{G} d \mathrm{~A} d \mathrm{CT}^{\mathrm{L}}$ \\
\hline
\end{tabular}

Table 2 Differences between hybridization buffers used for each type of probe

\begin{tabular}{lllll}
\hline Probe & Denaturant & {$\left[\mathrm{NA}^{\dagger}\right](\mathrm{mM})$} & Tris-HCl $(\mathrm{mM})$ & Other reagents \\
\hline HyP_DNA & $30 \%(v / v) \mathrm{FA}$ & 900 & 20 & - \\
& $0.001 \%(v / v)$ SDS & & & \\
HyP_PNA & $30 \%(v / v) \mathrm{FA}$ & 10 & 50 & $0.1 \%(v / v)$ Triton-X $10 \%(v / v)$ dextran sulphate $5 \mathrm{mM}$ of EDTA \\
HyP_LNA & 4 M urea & 900 & 50 & \\
\hline
\end{tabular}

FA formamide 
Table 3 Melting temperatures, $\operatorname{Tm}\left({ }^{\circ} \mathrm{C}\right)$, and mismatch $(\mathrm{C}>\mathrm{T} / \mathrm{U})$ discrimination temperature difference. $\Delta T_{m}$ in different buffers for DNA complementary target in $110 \mathrm{mM} \mathrm{Na}^{+}$buffer $^{\mathrm{a}}, 10$ $\mathrm{mM} \mathrm{Na}^{+}$buffer with $30 \%(v / v)$ formamide, and $900 \mathrm{mM} \mathrm{Na}^{+}$buffer with $4 \mathrm{M}$ urea

\begin{tabular}{|c|c|c|c|c|c|c|}
\hline \multirow[b]{3}{*}{ Name } & \multicolumn{6}{|c|}{$T_{m}$ at total $\left[\mathrm{Na}^{+}\right]$indicated } \\
\hline & \multicolumn{2}{|c|}{$110 \mathrm{mM}$} & \multicolumn{2}{|c|}{$10 \mathrm{mM}$} & \multicolumn{2}{|c|}{$900 \mathrm{mM}$} \\
\hline & $T_{m}$ & $\Delta T_{m}$ & $T_{m}$ & $\Delta T_{m}$ & $T_{m}$ & $\Delta T_{m}$ \\
\hline Reference & 52.3 & 6.9 & 37.4 & 1.3 & 56.6 & 8.2 \\
\hline HyP_DNA & 48.9 & 8.4 & 33.5 & 6.9 & 51.5 & 8.9 \\
\hline HyP_PNA & 64.6 & 15.3 & 42.7 & 16.5 & 60.9 & 17.2 \\
\hline HyP_LNA/UNA1 & 17.4 & $\mathrm{nb}$ & 15.3 & $\mathrm{nb}$ & 42.1 & $\mathrm{nb}$ \\
\hline HyP_LNA/UNA2 & 38.5 & 17.9 & 21.8 & 9.7 & 41.6 & 21.3 \\
\hline HyP_LNA/UNA3 & 35.5 & 14.2 & 20.5 & NT & 34.2 & 14.9 \\
\hline HyP_LNA/2'OMe1 & 59.1 & 12.1 & 47.6 & 17.3 & 70.8 & 10.2 \\
\hline HyP_LNA/2'OMe2 & 63.51 & 12.2 & 51.7 & 15.5 & 78.3 & 13.1 \\
\hline HyP_LNA/DNA1 & 57.5 & 20.3 & 44.6 & 17.3 & 60.7 & 13.2 \\
\hline HyP_LNA/DNA2 & 53.2 & 15.0 & 44.2 & 21.2 & 62.0 & 14.1 \\
\hline
\end{tabular}

$n b$ no binding could be detected 
Table 4 Melting temperatures, $\operatorname{Tm}\left({ }^{\circ} \mathrm{C}\right)$, mismatch $(\mathrm{C}>\mathrm{T} / \mathrm{U})$ discrimination temperature difference $(\Delta T m)$, and hybridization temperatures $T H\left({ }^{\circ} \mathrm{C}\right)$ at which each probe had highest sensitivity and specificity. $\Delta T m$ in different buffers for RNA complementary oligonucleotide: 110 $\mathrm{mM} \mathrm{Na}^{+}$buffer $^{\mathrm{a}}, 10 \mathrm{mM} \mathrm{Na}^{+}$buffer with $30 \%(v / v)$ formamide and $900 \mathrm{mM} \mathrm{Na}^{+}$buffer with 4 $\mathrm{M}$ urea

\begin{tabular}{|c|c|c|c|c|c|c|c|}
\hline \multirow[b]{3}{*}{ Name } & \multicolumn{6}{|c|}{$T_{\mathrm{m}}$ at total $\left[\mathrm{Na}^{+}\right]$indicated } & \multirow{3}{*}{$\begin{array}{l}\text { Hybridization temperature } \\
900 \mathrm{mM} \\
T_{H}\end{array}$} \\
\hline & \multicolumn{2}{|c|}{$110 \mathrm{mM}$} & \multicolumn{2}{|c|}{$10 \mathrm{mM}$} & \multicolumn{2}{|c|}{$900 \mathrm{mM}$} & \\
\hline & $T_{m}$ & $\Delta T_{m}$ & $T_{m}$ & $\Delta T_{m}$ & $T_{m}$ & $\Delta T_{m}$ & \\
\hline Reference & 49.3 & 3.3 & 35.2 & 5.1 & 52.6 & 9.1 & - \\
\hline HyP_DNA & 44.5 & 10.0 & 30.2 & 9.35 & 46.6 & 9.9 & 70 \\
\hline HyP_PNA & 67.6 & 13.2 & 44.6 & 15.6 & 62.4 & 11.4 & 45 \\
\hline HyP_LNA/UNA1 & 32.4 & $\mathrm{nb}$ & 32.1 & $\mathrm{nb}$ & 35.9 & 16.8 & 53 \\
\hline HyP_LNA/UNA2 & 53.7 & 13.8 & 38.1 & 15.3 & 59.6 & 13.3 & 53 \\
\hline HyP_LNA/UNA3 & 50.7 & 12.9 & 36.1 & 14.9 & 54.9 & 13.4 & 48 \\
\hline HyP_LNA/2'OMe1 & 69.4 & 13.3 & 57.8 & 15.9 & 78.9 & 18.1 & 60 \\
\hline HyP_LNA/2'OMe2 & 75.4 & 12.8 & 62.3 & 13.2 & 78.2 & 17.6 & 65 \\
\hline HyP_LNA/DNA1 & 66.4 & 13.5 & 54.2 & 14.1 & 71.4 & 11.5 & 43 \\
\hline HyP LNA/DNA2 & 62.1 & 12.8 & 47.9 & 14.4 & 67.4 & 13.9 & 40 \\
\hline
\end{tabular}

$n b$ no binding could be detected 